\title{
BIBLIOGRAPHY OF NORBERT WIENER
}

1. On the rearrangement of the positive integers in a series of ordinal numbers greater than that of any given fundamental sequence of omegas, Messenger of Math. 3 (1913), No. 511.

2. The highest good, J. Phil. Psych. and Sci. Method 9 (1914), 512-520.

3. Relativism, J. Phil. Psych. and Sci. Method 9 (1914), 561-577.

4. A simplification of the logic of relations, Proc. Cambridge Philos. Soc. 27 (1914), 387-390.

5. A contribution to the theory of relative position, Proc. Cambridge Philos. Soc. 27 (1914), 441-449.

6. Studies in synthetic logic, Proc. Cambridge Philos. Soc. 18 (1915), 24-28.

7. The shortest line dividing an area in a given ratio, J. Phil. Psych. and Sci. Method (1915), 567-574.

8. Certain formal invariance in Boolean algebras, Trans. Amer. Math. Soc. 18 (1917), 65-72.

9. Bilinear operations generating all operations rational in a domain, Ann. of Math. 21 (1920), 157-165.

10. A set of postulates for fields, Trans. Amer. Math. Soc. 21 (1920), 237-246.

11. Certain iterative characteristics of bilinear operations, Bull. Amer. Math. Soc. 27 (1920), 6-10.

12. The mean of a functional of arbitrary elements, Ann. of Math. (2) 22 (1920), 66-72.

13. On the theory of sets of points in terms of continuous transformations, G. R. Strasbourg Math. Congress, 1920.

14. Certain iterative properties of bilinear operations, G. R. Strasbourg Math. Congress, 1920.

15. A new theory of measurement: $A$ study in the logic of mathematics, Proc. London Math. Soc. 19 (1921), 181-205.

16. A new vector in integral equations (with F. L. Hitchcock), J. Math. and Phys. 1 (1921), 20 pp.

17. The average of an analytical functional, Proc. Nat. Acad. Sci. U.S.A. 7 (1921), 253-260.

18. The average of an analytical functional and the Brownian movement, Proc. Nat. Acad. Sci. U.S.A. 7 (1921), 294-298.

19. The isomorphisms of complex algebra, Bull. Amer. Math. Soc. 27 (1921), 443-445.

20. The relation of space and geometry to experience, Monist. 32 (1922), 12-60; 200-247; 364-394. 
21. The group of the linear continuum, Proc. London Math. Soc. 20 (1922), 329-346.

22. A new type of integral expansion, J. Math. and Phys. 1 (1922), 167-176.

23. Limit in terms of continuous transformation, Bull. Soc. Math. France (1922), 119-134.

24. Certain notions in potential theory, J. Math. and Phys. 3 (1924), 24-51.

25. The equivalence of expansions in terms of orthogonal functions (with J. L. Walsh), J. Math. and Phys. 1 (1922), 103-122.

26. On the nature of mathematical thinking, Austral. J. Psych. and Phil. 1 (1923), 268-272.

27. Note on a paper of M. Banach, Fund. Math. 4 (1923), 136-143.

28. Nets and the Dirichlet problem (with H. B. Phillips), J. Math. and Phys. 2 (1923), 105-124.

29. Differential space, J. Math. and Phys. 2 (1923), 131-174.

30. Note on a new type of summability, Amer. J. Math. 45 (1923), 83-86.

31. Discontinuous boundary conditions and the Dirichlet problem, Trans. Amer. Math. Soc. 25 (1923), 307-314.

32. Note on the series $\sum(+1 / n)$, Bull. Acad. Polon. Ser. A (1923), $87-90$.

33. In memory of Joseph Lipka, J. Math. and Phys. 3 (1924), 63-65.

34. The quadratic variation of a function and its Fourier coefficients, J. Math. and Phys. 3 (1924), 72-94.

35. The Dirichlet problem, J. Math. and Phys. 3 (1924), 127-147.

36. Une condition nécessaire et suffisante de possibilitê pour le problème de Dirichlet, C. R. Acad. Sci. Paris 178 (1924), 1050-1053.

37. The average value of a functional, Proc. London Math. Soc. 22 (1924), 454-467.

38. Un problème de probabilités dénombrables, Bull. Soc. Math. France 11 (1924), 3-4.

39. Note on a paper of O. Perron, J. Math. and Phys. 4 (1925), 21-32.

40. The solution of a difference equation by trigonometrical integrals, J. Math. and Phys. 4 (1925), 153-163.

41. A contribution to the theory of interpolation, Ann. of Math. (2) 26 (1925), 212-116.

42. Note on quasi-analytic functions, J. Math. and Phys. 4 (1925), 193-199.

43. On the representation of functions by trigonometrical integrals, Math. Z. 24 (1925), 576-616.

44. Verallgemeinerte Trigonometrische Entwicklungen, Gott. Nachrichten (1925), 151-158. 
45. A new formulation of the laws of quantization for periodic and aperiodic phenomena (with M. Born), J. Math. and Phys. 5 (1926), 84-98.

46. Eine neue Formulierung der Quantengesetze fur Periodische und nicht Periodische Borganze, Z. Physik 36 (1926), 174-187.

47. The harmonic analysis of irregular motion, J. Math. and Phys. 5 (1926), 99-121.

48. The harmonic analysis of irregular motion (Second Paper), J. Math. and Phys. 5 (1926), 158-189.

49. The operational calculus, Math. Ann. 95 (1926), 557-584.

50. Analytical approximations to topological transformations (with P. Franklin), Trans. Amer. Math. Soc. 28 (1926), 762-785.

51. On the closure of certain assemblages of trigonometrical functions, Proc. Nat. Acad. Sci. 13 (1927), 27-29.

52. Laplacians and continuous linear functionals, Acta Sci. Math. (Szeged) 3 (1927), 7-16.

53. The spectrum of an array and its application to the study of the translation properties of a simple class of arithmetical functions, J. Math. and Phys. 6 (1927), 145-157.

54. Quantum theory and gravitational relativity (with D. J. Struik), Nature 119 (1927), 853-854.

55. A relativistic theory of quanta (with $\mathrm{D}$. J. Struik), J. Math. and Phys. 7 (1927), 1-23.

56. Sur la théorie relativiste des quanta (with D. J. Struik), C. R. Acad. Sci. Paris 185 (1927), 42-44.

57. On a new definition of almost periodic functions, Ann. of Math. (2) 28 (1927), 365-367.

58. On a theorem of Bochner and Hardy, J. London Math. Soc. 2 (1927), 118-123.

59. Sur la thêorie relativiste des quanta, C. R. Acad. Sci. Paris 185 (1927), 184-185.

60. Une généralisation des fonctionelles a variation bornée, $\mathrm{C}$. R. Acad. Sci. Paris 185 (1927), 65-67.

61. Une méthode nouvelle pour la démonstration des théorèms de Tauber, C. R. Acad. Sci. Paris 184 (1927), 793-795.

62. The fifth dimension in relativistic quantum theory (with D. J. Struik), Proc. Nat. Acad. Sci. 14 (1928), 262-268.

63. The spectrum of an arbitrary function, Proc. London Math. Soc. 27 (1928), 287-496.

64. Coherency matrices and quantum theory, J. Math. and Phys. 1 (1928), 109-125.

65. A new method of Tauberian theorems, J. Math. and Phys. 7 (1928), 161-184. 
66. Harmonic analysis and the quantum theory, J. Franklin Inst. 207 (1929), 525-534.

67. Hermitian polynomials and Fourier analysis, J. Math. and Phys. 8 (1929), 70-73.

68. Harmonic analysis and group theory, J. Math. and Phys. 8 (1929), 148-154.

69. On the spherically symmetrical statistical field in Einstein's unified theory of electricity and gravitation, Proc. Nat. Acad. Sci. 15 (1929), 353-356.

70. On the spherically symmetrical statistical field in Einstein's unified theory: A correction (with M. S. Vallarta), Proc. Nat. Acad. Sci. 15 (1929), 802-804.

71. A type of Tauberian theorem applying to Fourier series, Proc. London Math. Soc. 30 (1929), 1-8.

72. Fourier analysis and asymptotic series, Operational circuit analysis by V. Bush, Wiley, New York, 1929; Appendix, pp. 366-379.

73. Generalized harmonic analysis, Acta Math. 55 (1930), 117-258.

74. Tauberian theorems, Ann. of Math. 33 (1932), 1-100.

75. A note on tauberian theorems, Ann. of Math. 33 (1932), 787.

76. A new deduction of the Gaussian distribution, J. Math. and Phys. 10 (1931), 284-288.

77. Characters of infinite Abelian groups (with R. E. A. C. Paley), Int'l. Math. Congr., Zürich, 1932.

78. Über eine Klasse Singulärer Integralgleichungen (with E. Hopf), S.-B. Preuss. Akad. Wiss. (1932), 696.

79. Review: Harald Bohr. Fastperiodische Funktionen, Math. Gaz. 17 (1933), No. 54.

80. Review: A. S. Besicovitch. Almost periodic functions, Math. Gaz. 16 (1932), No. 220.

81. The Fourier integral and certain of its applications, Cambridge Univ. Press, New York, 1933; reprint, Dover, New York, 1959; Math. Rev. 20 (1959), rev. no. 6634.

82. Notes on the theory and application of Fourier transforms (with R. E. A. C. Paley) I, II, Trans. Amer. Math. Soc. 35 (1933), 348-355; III, IV, V, VI, VII, ibid. 35 (1933), 761-791.

83. A one-sided Tauberian theorem, Math. Z. 36 (1933), 787-789.

84. R. E. A. C. Paley-In memoriam, Bull. Amer. Math. Soc. 39 (1933), 476.

85. Characters of Abelian groups (with R. E. A. C. Paley), Proc. Nat. Acad. Sci. 19 (1933), 253-257.

86. Review: E. C. Titchmarsh, The Fourier integral and certain of its applications, Math. Gaz. 17 (1933), 129; Science 132 (1933), 731. 
87. Notes on random functions (with R. E. A. C. Paley and A. Z. Zygmund), Math. Z. 37 (1933), 647-668.

88. The total variation of $g(x h)-f(x)$ (with R. C. Young), Trans. Amer. Math. Soc. 35 (1933), 327-340.

89. Leibnitz and Haldane, Philos. Sci. 1 (1934), No. 4.

90. Notes on the Kron theory of tensors in electrical machinery, Abstract, J. Electr. Eng. China 7, 3-4.

91. A class of gap theorems, Ann. Scuola Norm. Sup. Pisa, E (19341936), 1-6.

92. Fourier transforms in the complex domain (with R. E. A. C. Paley), Amer. Math. Soc. Colloq. Publ., Vol. 19, Amer. Math. Soc., Providence, R. I., 1934.

93. Random functions, J. Math. and Phys. 14 (1934), No. 1.

94. The closure of Bessel functions. Abstract 66, Bull. Amer. Math. Soc. 41 (1935), 35.

95. Fabry's gap theorem, Sci. Repts. of Nat'l. Tsing Hua Univ., Ser. A, 3 (1935), 239-245.

96. A theorem of Carleman, Sci. Repts. of Nat'l. Tsing Hua Univ., Ser. A, 3 (1935), 291-298.

97. Math. in American secondary schools, J. Math. Assoc. Japan for Secondary Education, Tokyo, 1935.

98. The role of the observer, Philos. Sci. 3 (1936), 307-319.

99. Sur les sêries de Fourier lacunaires. Thêorème direct (with Szolem Mandelbrojt), C. R. Acad. Sci. Paris 203 (1936), 34-36.

100. Séries de Fourier lacunaires. Thêorème inverses, with Szolem Mandelbrojt, C. R. Acad. Sci. Paris 203 (1936), 233-234.

101. Gap theorems, C. R. de Congr. Int'l. des Math., 1936.

102. A Tauberian gap theorem of Hardy and Littlewood, J. Chinese Math. Soc. 1 (1936), 15.

103. Taylor's series of entire functions of smooth growth (with W. T. Martin), Duke Math. J. 3 (1937), 213-223.

104. Random Waring's theorems. Abstract (with N. Levinson), Science 85 (1937), 439.

105. On absolutely convergent Fourier-Stieltjes transforms (with H. R. Pitt), Duke Math. J. 4 (1938), No. 2.

106. Fourier-Stieltjes transforms and singular infinite convolutions (with Aurel Wintner), Amer. J. Math. 60 (1938), No. 3.

107. Remarks on the classical inversion formula for the Laplace integral (with D. V. Widder), Bull. Amer. Math. Soc. 44 (1938), 573.

108. The homogeneous chaos, Amer. J. Math. 60 (1938), 897-936.

109. The decline of cookbook engineering, Tech. Rev. 41 (1938), 23.

110. Review: L. Hogben, Science for the citizen, Tech. Rev. 41 (1938), 66-67. 
111. The historical background of harmonic analysis, Amer. Math. Soc. Semicentennial Publications Vol. II, Semicentennial Addresses, Amer. Math. Soc., Providence, R. I., 1938.

112. Review: Roger Burlingame, March of the iron men, Tech. Rev. 41 (1939), 115.

113. Convergence properties of analytic functions of Fourier-Stieltjes transforms (with R. H. Cameron), Trans. Amer. Math. Soc. 46 (1939), 97-109; Math. Rev. 1 (1940), 13; 400.

114. Generalization of Ikehara's theorem (with J. R. Pitt), J. Math. and Phys. 17 (1939), No. 4.

115. On singular distribution (with Aurel Wintner), J. Math. and Phys. 17 (1939), No. 4.

116. A new method in statistical mechanics (with B. McMillan), Abstract 133, Bull. Amer. Math. Soc. 45 (1939), 234; Science 90 (1939), November 3.

117. The ergodic theorem, Duke Math. J. 5 (1939), 1-18.

118. The use of statistical theory in the study of turbulence, Nature 144 (1939), 728.

119. A canonical series for symmetric functions in statistical mechanics. Abstract 133, Bull. Amer. Math. Soc. 46 (1940), 57.

120. Review: M. Fukamiya, On dominated ergodic theorems in $L_{p}(p \geq 1)$, Math. Rev. 1 (1940), 148.

121. Review: M. Fukamiya, The Lipschitz condition of random functions, Math. Rev. 1 (1940), 149.

122. Review: Th. De Donder, L'énergétique déduite de la mécanique statistique générale, Math. Rev. 1 (1940), 192.

123. Harmonic analysis and ergodic theory (with Aurel Wintner), Amer. J. Math. 63 (1941), 415-426; Math. Rev. 2 (1941), 319.

124. On the ergodic dynamics of almost periodic systems (with Aurel Wintner), Amer. J. Math. 63 (1941), 794-824.

125. On the oscillation of the derivatives of a periodic function (with George Pólya), Trans. Amer. Math. Soc. 52 (1942), 249-256.

126. Ergodic dynamics of almost periodic systems (with Aurel Wintner), Math. Rev. 4 (1943), 15 (same as reference 124 above).

127. Behavior, purpose, and teleology (with Arturo Rosenblueth and J. Bigelow), Philos. Sci. 10 (1943), 18-24.

128. The discrete chaos (with Aurel Wintner), Amer. J. Math. 65, 279-298; Math. Rev. 4 (1943), 220.

129. The role of models in science (with Arturo Rosenblueth), Philos. Sci. 12 (1945), 316-322.

130. La teoria de la extrapolacion estadistica, Bol. Soc. Mat. Mexicana 2 (1945), 37-42; Math. Rev. 7 (1946), 461.

131. The mathematical formulation of the problem of conduction of im- 
pulses in a network of connected excitable elements, specifically in cardiac muscle (with Arturo Rosenblueth), Arch. Inst. Cardiol. Méxicana 16 (1946), 205-265; Bol. Soc. Mat. Mexicana 2 (1945), 37-42; Math. Rev. 9 (1948), 604.

132. Theory of statistical extrapolation, Math. Rev. 7 (1946), 416 (same as reference 130 above).

133. A generalization of the Wiener-Hopf integral equation (with Albert E. Heins), Proc. Nat. Acad. Sci. U.S.A. 32 (1946), 98-101; Math. Rev. 8 (1947), 29.

134. Sur les fonctions indéfiniment dérivables sur une demi-droite (with Szolem Mandelbrojt), C. R. Acad. Sci. Paris 225 (1947), 978980; Math. Rev. 9 (1948), 230.

135. A scientist rebels, Atlantic Monthly 179 (1947), 46.

136. Teleological mechanisms (with L. K. Frank, G. E. Hutchinson, W. K. Livingston, and W. S. McCulloch), Ann. New York Acad. Sci. 50 (1948), 187-278.

137. Review: L. Infeld, Whom the Gods love: The story of Evariste Galois, Scripta Math. 14 (1948), 273-274.

138. Cybernetics, or control and communication in the animal and the machine, Actualités Sci. Ind., no. 1053; Hermann et Cie., Paris; The MIT Press, Cambridge, Mass. and Wiley, New York, 1948; Math. Rev. 9 (1948), 598.

139. A rebellious scientist after two years, Bull. Atomic Scientists 4 (1948), 338.

140. Time, communication and the nervous system, Ann. New York Acad. Sci. 50 (1948), 197-220; Math. Rev. 10 (1949), 133.

141. Cybernetics, Scientific American 179 (1948), 14-18.

142. An account of the spike potential of axons (with Arturo Rosenblueth, W. Pitts, and J. Garcia Ramos), J. Comp. Physiol. (1948), December.

143. Sur la théorie de la prévision statistique et du filtrage des ondes, Analyse Harmonique, Colloques Internationaux du CNRS, No. 15, pp. 67-74. Centre National de la Recherche Scientifique, Paris, 1949; Math. Rev. 11 (1950), 376.

144. Extrapolation, interpolation, and smoothing of stationary time series. With engineering applications, The MIT Press, Cambridge, Mass.; Wiley, New York; Chapman \& Hall, London, 1949; Math. Rev. 11 (1950), 118.

145. New concept of communication engineering, Electronics 22 (1949), 74-77.

146. Obituary: Godfrey Harold Hardy (1877-1947), Bull. Amer. Math. Soc. 55 (1949), 72-77; Math. Rev. 10 (1949), 420. 
147. Sound communication with the deaf, Philos. Sci. 16 (1949), No. 3.

148. Some problems in sensory prosthesis (with L. Levine), Science 110 (1949), November 11.

149. The thinking machine, Time 55 (1950), January 23.

150. Some prime-number consequences of the Ikehara theorem (with Leonard Geller), Acta Sci. Math. (Szeged) 12, Leopoldo Fejer et Frederico Riesz LXX annos natis dedicatus, Pars B, 25-28 (1950); Math. Rev. 11 (1950), 644; ibid 12 (1951), 1002.

151. The human use of human beings, Houghton Mifflin, Boston, 1950 (paperback edition (Anchor) by Doubleday, 1954).

152. Cybernetics, Bull. Amer. Acad. Arts and Sci. 3 (1950), No. 7.

153. Some maxims for biologists and psychologists, Dialectica 4 (September 1950), 3.

154. Purposeful and non-purposeful behavior (with Arturo Rosenblueth), Philos. Sci. (1950), October.

155. Speech, language, and learning, J. Acoust. Soc. Amer. 22 (1950), 696-697.

156. Comprehensive view of prediction theory, Proceedings of the International Congress of Mathematicians, Cambridge, Mass., 1950, Vol. 2, pp. 308-321; Amer. Math. Soc., Providence, R. I., 1952, Expository lecture; Math. Rev. 13 (1952), 477.

157. Entropy and information, Proc. Sympos. Appl. Math., Vol. 2, Amer. Math. Soc., Providence, R. I., 1950; p. 89; Math. Rev. 11 (1950), 305.

158. Problems of sensory prosthesis, Bull. Amer. Math. Soc. 57 (1951), 27-35.

159. Homeostasis in the individual and society, J. Franklin Inst. 251 (1951), No. 1.

160. The brain (ss), Tech. Eng. News (1952), April; reprinted in paperback anthology, Crossroads in Time, ed. Groff Conklin, Doubleday, New York, 1953.

161. Les machines à calculer et la forme (Gestalt), Les machines à calculer et la pensée humaine, Colloques Internationaux du Centre National de la Recherche Scientifique, Paris, 1953; pp. 461463; Math. Rev. 16 (1955), 529.

162. A new form for the statistical postulate of quantum mechanics (with Armand Siegel), Phys. Rev. 91 (1953), 1551-1560; Math. Rev. 15 (1954), 273.

163. Distributions quantiques dans l'espace différentiel pour les fonctions d'ondes dépendant du spin, C. R. Acad. Sci. Paris 237 (1953), 1640-1642; Math. Rev. 15 (1954), 490.

164. Miracle of the broom closet (ss), Tech. Eng. News 33 (1952), No. 
7; reprinted in the Magazine of Fantasy and Science Fiction, ed. Anthony Boucher, February, 1954.

165. Ex-prodigy: my childhood and youth, Simon and Schuster, New York, 1953; The MIT Press, Cambridge, Mass. 1965 (also paperback edition by MIT Press); Math. Rev. 15 (1954), 277.

166. The concept of homeostasis in medicine, Transactions and Studies of the College of Physicians of Philadelphia (4) 20 (1953), No. 3.

167. The differential space theory of quantum mechanics (with Armand Siegel), Phys. Rev. 91 (1953), 1551.

168. Optics and the theory of stochastic processes, J. Opt. Soc. Amer. 43 (1953); 225-228; Math. Rev. 17 (1956), 33.

169. The future of automatic machinery, Mechanical Engineering (1953), 130-132, February.

170. Nonlinear prediction and dynamics, Proc. Third Berkeley Symposium on Mathematical Statistics and Probability, University of California Press, 1954; Math. Rev. 18 (1957), 949.

171. The differential space theory of quantum systems (with Armand Siegel), Nuovo Cimento (10) 2 (1955), 982-1003, No. 4, Suppl.

172. On the factorization of matrices, Comment. Math. Helv. 29 (1955), 97-111; Math. Rev. 16 (1955), 921.

173. Thermodynamics of the message, Neurochemistry, ed. K. E. C. Elliott, Thomas, Springfield, 1955.

174. Time and organization, Second Fawley Foundation Lecture, University of Southampton, 1955.

175. The "Theory of measurement" in differential space quantum theory (with Armand Siegel), Phys. Rev. 101 (1956), 429-432.

176. The theory of prediction, Modern mathematics for the engineer, ed. E. F. Beckenbach, McGraw-Hill, New York, 1956.

177. I am a mathematician. The later life of a prodigy, Doubleday, Garden City, New York, 1956 (paperback edition by The MIT Press); Math. Rev. 17 (1956), 1037.

178. Brain waves and the interferometer, J. Phys. Soc. Japan 18 (1956), No. 8.

179. Moral reflections of a mathematician, Bull. Atomic Scientists 12 (1956), 53-57; reprinted from I am a mathematician.

180. Rhythms in physiology with particular reference to encephalography. Proceedings of the Rudolf Virchow Medical Society in the City of New York, Vol. 16, 1957; pp. 109-124.

181. The definition and ergodic properties of the stochastic adjoint of a unitary transformation (with E. J. Akutowicz), Rend. Circ. Mat. Palermo (2) 6 (1957), 205-217, Addendum, 349; Math. Rev. 20 (1959), rev. no. 4328.

182. Notes on Pólya's and Turan's hypotheses concerning Liouville's 
factor, Rend. Circ. Mat. Palermo (2) 6 (1957), 240-248; Math. Rev. 20 (1959), rev. no. 5759.

183. The role of the mathematician in a materialistic culture ( $A$ scientist's dilemma in a materialistic world), Columbia Engineering Quarterly, Proceedings of the Second Combined Plan Conference, Arden House, October 6-9, 1957; pp. 22-24.

184. On the non-vanishing of Euler products (with Aurel Wintner), Amer. J. Math. 79 (1957), 801-808.

185. The prediction theory of multivariate stochastic processes. I. The regularity condition (with P. Masani), Acta Math. 98 (1957), 111-150; Math. Rev. 20 (1959), rev. no. 4323.

186. The prediction theory of multivariate stochastic processes. II. The linear predictor (with P. Masani), Acta Math. 99 (1958), 93137; Math. Rev. 20 (1959), rev. no. 4325.

187. Logique, probabilité et méthode des sciences physiques, La Methodes dans les Sciences Modernes, Editions Science et Industrie, ed. François Le Lionnais, Paris, 1958; pp. 111-112.

188. My connection with cybernetics. Its origin and its future, Cybernetica (1958), 1-14.

189. Random time, Nature 181 (1958), 561-562.

190. Time and the science of organization, Scientia (1958), September.

191. Nonlinear problems in random theory, The MIT Press, Cambridge, Mass., and Wiley, New York 1958; Math. Rev. 20 (1959), rev. no. 7337.

192. Sur la prêvision linéaire des processus stochastiques vectoriels d densitê spectrale bornée. I (with P. Masani), C. R. Acad. Sci. Paris 246 (1958), 1492-1495; Math. Rev. 20 (1959), rev. no. 4324a.

193. Sur la prévision linéaire des processus stochastiques vectoriels a densité spectrale bornée. II (with P. Masani), C. R. Acad. Sci. Paris 246 (1958), 1655-1656; Math. Rev. 20 (1959), rev. no. $4324 \mathrm{~b}$.

194. A factorization of positive Hermitian matrices (with E. J. Akutowicz), J. Math. Mech. 8 (1959), 111-120.

195. The tempter, Random House, New York, 1959.

196. Non-linear prediction (in "Probability and statistics") (with P. Masani), The Harald Cramer Volume, ed. U. Grenander, Stockholm, 1959.

197. On bivariate stationary processes and the factorization of matrixvalued functions (with P. Masani), Theory of Probability and its Applications (Moscow) 4 (1959), 322-331; (English transl., pp. 300-308).

198. Preface to "Cybernetics of natural systems" by D. StanleyJones, Pergamon Press, London, 1960. 
199. "The grand privilege," Saturday Review (1960), March 5.

200. Some moral and technical consequences of automation, Science 131 (1960).

201. Kybernetik, Contribution to Das Soziologische Wörterbuch, F. Enke Verlag, Stuttgart, 1960.

202. Ueber Informationstheorie, Naturwissenschaften 7 (1961), 174176.

203. Science and society, Voprosy Filosofii (1961), No. 7.

204. Cybernetics, Second edition, The MIT Press and Wiley, New York, 1961, (also paperback edition by MIT Press).

205. L'homme et la machine, Proc. Colloques Philosophiques Internationaux de Royaumont, July, 1962; Le concept d'information dans la science contemporaine, Gauthier-Villars, Paris, 1965, pp. 99-132.

206. Contribution to Proc. of the International Symposium on the Application of Automatic Control in Prosthetics Design, August 27-31, 1962, Opatija, Yugoslavia; p. 132.

207. The mathematics of self-organizing systems, Recent developments in information and decision processes, Macmillan, New York, 1962.

208. Introduction to neurocybernetics and Epilogue (With J. P. Schade), Progress in brain research, Vol. 2 (Nerve, Brain and Memory Models), Elsevier Publishing Co., Amsterdam, 1963, pp. 1-7, 264-268.

209. Random theory in classical phase space and quantum mechanics (with Giacomo della Riccia), Proc. Internat. Conference on Functional Analysis, Massachusetts Institute of Technology, Cambridge, Mass., June 9-13, 1963; Analysis in function space, pp. 3-14, The MIT Press, Cambridge, Mass. 1964.

210. On the oscillations of nonlinear systems, Proc. Symposium on Stochastic Models in Medicine and Biology, Mathematics Research Center, U. S. Army, June 12-14, 1963.

211. God and Golem, Inc.: A comment on certain points where cybernetics impinges on religion, The MIT Press, Cambridge, Mass., 1964.

212. Dynamical systems in physics and biology, Contribution to series "Fundamental Science in 1984," The New Scientist, London, 1964.

213. Reprinting of [143] as Time series, Wiley paperbacks, 1964 (paperback edition by The MIT Press).

214. Selected papers of Norbert Wiener: Expository papers by Y. W. Lee, Norman Levinson, and W. T. Martin, The MIT Press, Cambridge, Mass., 1964. 